\title{
Um Estudo Exploratório sobre um Novo Tipo de Empreendimento: os Spin-offs Acadêmicos
}

\section{An Exploratory Study about a New Kind of Enterprise: the Academic Spin-offs}

Lucelia Borges da Costa* Doutoranda em Engenharia de Produção pela UFSCAR, São Carlos/SP, Brasil.

Ana Lúcia Vitale Torkomian

Doutora em Administração de Empresas pela FEA/USP. Professora do Departamento de Engenharia de Produção da UFSCAR, São Carlos/SP, Brasil.

*Endereço: Rua Calimério Martinez, 451, Jacobucci, São Carlos/SP, 13567-150. E-mail: lucelia@dep.ufscar.br 


\section{ResUmo}

Este artigo almeja apresentar o perfil dos spin-offs acadêmicos do Brasil. A metodologia utilizada foi a pesquisa exploratória e os dados foram coletados por meio de questionários enviados a 33 spin-offs de 9 universidades. Embora exista uma limitação devido ao número de empresas analisadas, o objetivo principal foi atingido satisfatoriamente. Os resultados obtidos apresentam as características, motivações e dificuldades dos spin-offs.

Palavras-chave: spin-offs acadêmicos; transferência de tecnologia; cooperação universidade-empresa.

\section{Abstract}

This paper aims to present the profile of Brazil's academic spin-offs. The methodology used was the exploratory research and the data was collected through questionnaires sent to 33 academic spin-offs from 9 universities. Although there is a constraint due to the number of analysed companies, the proposed aim was successfully achieved . The results obtained present the spin-offs' characteristics, motivations and difficulties.

Key words: academic spin-offs; transfer of technology; university-company cooperation. 


\section{INTRODUÇÃO}

Por muito tempo a universidade esteve com suas portas fechadas à sociedade e pouco se sabia a respeito do que ocorria dentro de suas paredes. Entretanto esta situação começou a mudar no final do século XIX, quando o meio acadêmico passou a atuar cooperativamente com as diversas indústrias.

Hoje, percebe-se a existência de diversos mecanismos de transferência de conhecimento e tecnologia, ganhando destaque a criação de empresas a partir de resultado de pesquisa, os spin-offs acadêmicos.

Buscando compreender melhor este mecanismo, o presente estudo tem como objetivo analisar como se caracterizam as empresas criadas a partir de resultados de pesquisas geradas em universidades, ou seja, buscar entender qual é o perfil dos spin-offs acadêmicos brasileiros.

A base que dá sustentação a esta pesquisa é composta por três argumentos. Primeiro, as pesquisas realizadas dentro das universidades, além de estar focadas no conhecimento básico, devem ter ligações com o cotidiano da sociedade para que possam ser mais bem aproveitadas.

Segundo, a criação de spin-offs acadêmicos possibilita a geração de empregos altamente qualificados, gera divisas para o país e cria maior dinâmica inovativa dentro da indústria nacional.

E por último, a transferência de tecnologia da universidade para a indústria, por meio do processo spin-off, traz benefícios tanto econômicos quanto intelectuais para o meio acadêmico brasileiro.

\section{TransferênCIA DE TeCNOLOGIA}

A transferência de tecnologia das universidades para o setor privado contribui significativamente para a criação de novos negócios e de novos empregos, promove avanços tecnológicos e leva ao aumento da riqueza social, isto porque o conhecimento só gera valor e benefícios sociais, quando é transferido de seu meio de produção para a sociedade (Harmon et al., 1997).

Segundo Carayannis, Rogers, Kurihara e Albritton (1998), a transferência de 
tecnologia da universidade para as empresas ocorre mediante uma variedade de canais de comunicação, como publicações, conferências, licenciamento de direitos de propriedade intelectual, e movimento de pessoas.

\section{Conceituação}

Para Prysthon e Schmidt (2002, p. 87), "a verdadeira transferência de tecnologia ocorre quando o receptor absorve o conjunto de conhecimento que lhe permite inovar, isto é, a transferência se completa quando o comprador (cliente/usuário) domina o conhecimento envolvido, transpõe barreiras e fica em condições de criar novas tecnologias, gerando mais conhecimentos, transformando, inovando, criando".

Para Souza (1983), a transferência de tecnologia consiste no deslocamento de um conjunto de conhecimento e práticas tecnológicas de uma entidade para a outra. Ainda segundo o autor, há dois tipos de abordagem para transferência: a horizontal e a vertical. Sob a denominação de transferência horizontal de tecnologia, estudam-se os mecanismos de permuta e utilização de conhecimentos tecnológicos entre entidades semelhantes, como por exemplo, entre os institutos de pesquisas ou empresas industriais. Já a expressão transferência vertical de tecnologia referese àquela que ocorre entre instituições integradas verticalmente na economia, como entidades de P\&D, de engenharia básica, de engenharia de detalhe, de fabricação de equipamentos, de produção etc.

Complementando, Campomar (1983) afirma que a transferência horizontal ocorre pela adaptação de uma aplicação de certa tecnologia para outra atividade que não a original. E a vertical diz respeito à transferência de tecnologia ao longo da linha, indo do mais geral para o mais específico, e que em particular, é o processo pelo qual o conhecimento científico novo é transformado em tecnologia e o novo estado da arte é introduzido no sistema existente. Para o autor, a análise destes dois tipos de transferência de tecnologia mostra que geralmente a horizontal é um processo entre organizações, enquanto a vertical envolve atividades intraorganizações.

\section{Mecanismos de Transferência}

Segundo Sbragia (2003, p. 1), "há diversas maneiras de se levar um projeto de Pesquisa e Desenvolvimento [P\&D] realizado em ambiente acadêmico a uma produção em escala comercial. Pode ser feito por meio do licenciamento e/ou venda de resultados, por meio da associação com empresas inovadoras ou por meio da criação de empresas. Esta última alternativa, a criação de uma empresa surgida do ambiente universitário, deve-se ao fato de que as empresas já 
estabelecidas poucas vezes estão dispostas a correr os riscos associados ao desenvolvimento tecnológico".

Segundo Etzkowitz (1998), a transferência de tecnologia da universidade para a empresa é um fluxo de mão dupla e ele pode ocorrer com diferentes graus e formas de envolvimento acadêmico:

- produto é originado na universidade, mas é desenvolvido em uma empresa já existente;

. um produto comercial é originado fora da universidade, mas são requeridos conhecimentos acadêmicos para melhorá-lo; e

- a universidade é fonte de um produto comercial e o inventor acadêmico tornase diretamente envolvido em sua comercialização por meio do estabelecimento de uma nova empresa.

Rogers, Takegami e Yin (2001) apresentam cinco mecanismos de transferência tecnológica entre a academia e a indústria:

- Os contratos de cooperação em P\&D que ocorrem por meio do compartilhamento de pessoas envolvidas com pesquisas, equipamentos e direitos de propriedade intelectual.

- Encontros que envolvem a interação pessoa a pessoa em que a informação técnica é trocada. Existem diversas redes e associações que promovem estes encontros.

- As publicações científicas também podem ser um meio de transferência tecnológica. No entanto elas geralmente são escritas para parceiros cientistas, em vez de serem direcionadas aos usuários potenciais da pesquisa tecnológica.

- Licenciamento que consiste em transferir os direitos para fazer, usar e/ou vender certo produto, design ou processo, ou para efetuar uma quantidade de outras ações, por uma parte que tem o direito para dar tal permissão (Anon, 1995 como citado em Rogers et al., 2001).

- Spin-off acadêmico, ou seja, uma nova companhia que é formada (1) por indivíduos que antigamente eram empregados de uma organização de origem e (2) de onde a core technology foi transferida (Rogers \& Steffensen, 1999).

Um dos mecanismos que vêm ganhando destaque nos últimos anos são os spin-offs acadêmicos, pois eles criam nova dinâmica para o processo de desenvolvimento de um país, trazendo à sociedade conhecimentos que muitas 
vezes ficavam restritos às paredes do meio acadêmico, gerando avanços sociais por meio da criação de empregos e proporcionando melhorias econômicas ao produzir divisas para o Estado.

De acordo com Grynszpan (1999), os spin-offs têm sido tema de debate há muito tempo, mas observa-se que os resultados obtidos pelo Brasil ainda são ínfimos, se comparados com os obtidos pelos Estados Unidos e alguns países da Europa.

\section{SPIN-OFFS ACADÊMICOS}

Nos últimos anos, as instituições acadêmicas têm sido associadas ao crescimento das empresas de alta tecnologia (Upstill \& Symington, 2002). Uma das mais importantes contribuições das universidades são as empresas spin-offs, nas quais acadêmicos individualmente ou suas instituições como um todo formam uma companhia separada para explorar e comercializar o P\&D interno (Webster \& Etzkowitz, 1998).

Há 20 anos, em alguns países, as universidades começaram a encorajar o desenvolvimento de empresas spin-offs, como rota alternativa para a comercialização de suas tecnologias. Um dos pioneiros nesta empreitada foi o MIT, com uma média de 25 empresas surgidas dele a cada ano na década de 80 (Bray \& Lee, 2000).

Segundo Sánchez e Pérez (2000), as empresas criadas pelos acadêmicos constituem importante elemento dinamizador de uma economia, não tanto pelo emprego direto que podem chegar a criar, mas porque supõem o desenvolvimento de novos setores industriais ou de serviços e porque com sua transferência de tecnologia contribuem para melhorar a competitividade de outros setores.

Inicialmente a universidade transfere a tecnologia para os spin-offs e depois estes transferem para seus consumidores, completando o fluxo de transferência e beneficiando toda a sociedade (Pérez \& Sánchez, 2003).

Cabe ressaltar que, apesar de o empreendedorismo acadêmico ser um efetivo meio para realizar a transferência de tecnologia, ele não é o melhor em todas as circunstâncias (Goldfarb \& Henrekson, 2003); por isso se faz necessário que haja melhor compreensão deste mecanismo para que ele possa ser empregado corretamente. 


\section{Conceituação}

Inicialmente, é importante destacar que alguns fundadores de empresas spinoffs reagem negativamente ao termo spin-off, pois eles sentem que há a ênfase na dependência da organização de origem e que não há o reconhecimento dos sacrifícios em dinheiro, tempo e esforços geralmente requeridos para estabelecer nova empresa (Steffensen, Rogers, \& Speakman, 2000).

Além disso, há alguns autores que fazem distinção entre os termos spin-off e spin-out, mas para a maioria não existem diferenças reais entre eles (Steffensen et al., 2000). Uma das exceções são Duff e Hilton (1999), segundo os autores:

. spin-off - é uma empresa que surge de uma outra organização, mas que permanece possuída e administrada por seus geradores; e

- spin-out - é uma empresa que surge de outra organização, mas seu gerador não permanece como dono majoritário e portanto não exerce controle gerencial.

Para Huylebroeck (1999), uma empresa spin-off é uma empresa que não existiria se uma atividade de pesquisa específica não tivesse sido conduzida em uma organização baseada em conhecimento. Ainda de acordo com o autor, outras definições do termo são mais restritas e limitam empresas spin-offs àquelas companhias que são criadas por empregados que deixam seus antigos empregadores para explorar o conhecimento que eles adquiriram enquanto trabalhavam para aqueles empregadores.

De acordo com Steffensen et al. (2000), spin-off é uma empresa que surge de uma outra organização e que geralmente um empregado (ou empregados) deixa(m) a organização levando juntamente uma tecnologia que serve como ticket de entrada da nova empresa na indústria de alta tecnologia.

Ainda segundo o autor, o spin-off pode ser planejado ou espontâneo. O primeiro é uma empresa que resulta de um esforço realizado pela organização de origem. O outro é uma firma que resulta do esforço do empreendedor ao identificar uma oportunidade, onde há um encorajamento relativamente pequeno (e talvez um desencorajamento) da organização de origem.

Carayannis et al. (1998) e Rogers et al. (2001) definem spin-off como sendo uma empresa que foi estabelecida pela transferência de core technology pesquisadores, ou outros insumos de uma organização de origem. Ainda segundo Carayannis et al. (1998), um spin-off pode ser considerado um mecanismo de transferência de tecnologia, porque ele geralmente é formado para comercializar uma tecnologia que foi originada em um laboratório público de $\mathrm{P} \& \mathrm{D}$, uma universidade ou uma empresa privada. 
Para Carayannis et al. (1998), há quatro papéis principais envolvidos no processo de spin-off; o mesmo indivíduo ou organização pode desempenhar mais do que um papel:

. Gerador da tecnologia - quem traz a inovação tecnológica por meio de um processo de desenvolvimento inovativo até o ponto em que a transferência desta tecnologia pode ser iniciada.

. Empreendedor - quem se esforça para criar um novo negócio que é centrado na inovação tecnológica. O papel do empreendedor é comercializar a tecnologia em um produto ou serviço que é vendido em um mercado.

- A organização de origem - onde as atividades de P\&D para criar a inovação tecnológica ocorrem e que provêem aos spin-offs assistência em patenteamento da inovação, licenciamento tecnológico etc.

. Investidor - quem fornece os recursos financeiros para estabilizar o spin-off e que pode fornecer alguns conhecimentos administrativos.

Uma característica importante dos spin-offs é que eles podem ser categorizados de acordo com a organização da qual eles se originaram e de onde o empreendedor obteve suas experiências (Pérez \& Sánchez, 2003); uma das categorias que vem ganhando destaque nos últimos anos é a acadêmica.

Rappert, Webster e Charles (1999) afirmam que spin-offs acadêmicos são firmas cujos produtos ou serviços foram desenvolvidos de uma idéia tecnológica ou conhecimento técnico/científico originado em uma universidade por um membro da academia; este é quem cria a empresa. Complementando, Goldfarb e Henrekson (2003) apontam que os acadêmicos não precisam abandonar permanentemente suas posições nas universidades para poderem criar uma empresa.

A definição apresentada por Grandi e Grimaldi (2005) possui uma pequena diferença. Segundo os autores, a empresa spin-off também pode ser criada por alguém de fora da universidade, desde que seja licenciado para isto.

Para Brisolla (1998, p. 83), "o spin-off é um processo mediante o qual pesquisadores acadêmicos, geralmente como fruto de uma atividade de pesquisa que lhes parece promissora do ponto de vista prático, aventuram-se a assumir o papel de empresário ou associam-se a empresários interessados em assumir o risco de transformar sua idéia ou o resultado de sua pesquisa em produto. Geralmente isso é acompanhado pelo afastamento do cientista das universidades de origem ou pela redução de sua dedicação ao trabalho acadêmico". Sant'Anna (1994), ao conceituar o termo spin-off, aponta uma característica importante 
destas empresas. Para o autor, um spin-off acadêmico é uma empresa de base tecnológica criada por pesquisadores oriundos das universidades.

Um estudo de caso realizado por Sant'Anna (1994, p. 389) identificou a existência de dois tipos distintos de acadêmicos criadores de empresas de base tecnológica. "O primeiro tipo é o pesquisador que concebe o empreendimento, objetivando enriquecer sua atividade acadêmica, suprindo limitações das próprias universidades. Estes acadêmicos manifestam explicitamente sua vocação e sua intenção de permanecerem na universidade. As empresas criadas funcionam como apêndices das atividades acadêmicas, como fontes de informações que subsidiam o desenvolvimento de trabalhos científicos de cunho aplicado. O segundo tipo de acadêmico que cria empresa de base tecnológica é aquele que realmente encontra sua vocação na área empresarial e tende a se desligar da universidade". Um resultado importante do estudo é que as empresas que alcançaram o sucesso comercial e tecnológico pertencem aos pesquisadores que se enquadram na segunda categoria.

\section{Spin-offs Acadêmicos em Diversos Países}

No campo da produção e exploração do conhecimento existem muitas oportunidades para pequenas empresas de alta tecnologia, e atenção relevante é direcionada aos spin-offs de universidades e de institutos de pesquisa. Chiesa e Piccaluga (2000), a partir do levantamento de uma série de publicações, fazem uma ilustração sobre os spin-offs acadêmicos em diversos países, como se explicita a seguir.

França. No início dos anos oitenta muitos pesquisadores construíram empresas de alta tecnologia, principalmente de biotecnologia, inteligência artificial e robótica. Por meio de pesquisas realizadas em 1988 e 1994 verificou-se que na França cerca de um terço das novas empresas de alta tecnologia tem sido criadas por pesquisadores do setor público. Além disso, perceberam que o sucesso dos spinoffs depende especialmente da capacidade deles de estabelecer ligações com diferentes atores e setores: laboratórios de pesquisa, autoridades locais, clientes, outras empresas, instituições de financiamento etc.

Suécia. Observa-se que a maioria dos spin-offs acadêmicos é fundado por apenas 1 pessoa, somente um terço contém fundadores não acadêmicos e que menos de um terço tinha um produto bem definido quando a empresa foi fundada. Além disso, a maior parte dos fundadores é representada por pesquisadores com Ph.D. e que interromperam suas ligações com as universidades.

Escócia. Muitos spin-offs têm sidos fundados com vagas motivações comerciais e somente poucas foram iniciadas com o objetivo de um 
crescimento relevante. Uma das motivações dos fundadores é simplesmente continuar com a atividade de pesquisa deles e/ou providenciar algum trabalho para seus colaboradores. Entre as motivações da universidade a incentivar a geração de spin-offs inclui-se a geração de rendimentos para financiar departamentos ou o desejo de manter a motivação pessoal com maior espírito empreendedor.

Holanda. No final da década de 70 a universidade técnica inicia a implantação de políticas para os spin-offs, ajudando professores e outros a fundarem companhias baseadas em tecnologia. Este programa até 2000 já havia apoiado a criação de empregos de alta qualificação.

Itália. O sucesso dos spin-offs acadêmicos parece estar relacionado com dois fatores maiores: (1) se o pesquisador/empreendedor tem a possibilidade de usar os recursos da instituição de pesquisa de origem e/ou (2) se o produto já esta na etapa de protótipo, quando a universidade é abandonada. O status acadêmico italiano atua neste processo, influenciando os pesquisadores à escolha de soluções empreendedoras mais leves, ao invés de mudanças radicais, como o abandono das universidades, atitude típica que ocorre no sistema acadêmico norte-americano. O modelo italiano é caracterizado por baixo nível de risco, juntamente com modestas taxas de crescimento.

Segundo Bank Boston Economics Department (1997), o Massachusetts Institute of Technology [MIT] tem impactado a economia dos Estados Unidos com seus spin-offs. Um estudo realizado por ele identificou 4.000 empresas spin-offs do MIT que empregavam 1,1 milhão de pessoas, e geravam \$232 bilhões de vendas anuais. Segundo a pesquisa, desde 1990, 150 novas firmas têm surgido do MIT por ano. E se fosse constituída uma economia com as 4.000 empresas spin-offs do MIT ela seria a $24^{\mathrm{a}}$ maior economia nacional do mundo.

Outra importante descrição foi apresentada por Sánchez \& Pérez (2000). Segundo eles, em Aragón, Espanha, na Universidad de Zaragoza observa-se que há poucos spin-offs. Isto ocorre devido às dificuldades experimentadas pelos professores universitários em desenvolver alguma atividade empresarial, permanecendo na academia. Outra informação relevante é que os spin-offs acadêmicos existentes na região de Aragón dedicam uma porção superior a 10\% de seu faturamento a atividades de P\&D. Em 1997, com o objetivo de atuar, facilitando o desenvolvimento de empresas que surjam a partir de projetos universitários, surgiu na Espanha a Red Entreprenari Spin-off Académico. No período de 1997 a 1999, percebe-se que esta organização deu bons frutos, pois a Red contribuiu para a criação de 38 empresas inovadoras na Espanha. 


\section{Spin-offs Acadêmicos no Brasil}

Segundo Torkomian (1997), os spin-offs acadêmicos têm-se tornado um caminho cada vez mais natural para o aproveitamento de resultados de pesquisas. Os motivos que levam à sua formação são: a possibilidade de colocar no mercado uma tecnologia gerada, cuja transferência por outro meio é menos trivial; e a expectativa de obter ganhos financeiros.

Os dados de uma pesquisa realizada pela autora em duas universidades públicas brasileiras mostraram que nenhum pesquisador-empreendedor deixou suas atividades nas universidades para se aventurarem na criação de uma empresa, isso porque essas instituições lhes garantem estabilidade, proporcionam liberdade de trabalho e os colocam em contato com a elite intelectual do mundo inteiro. Além disso, os acadêmicos que tiveram que optar entre a empresa criada e a carreira universitária decidiram pela última. Em decorrência disso, acredita-se que o estímulo à formação de novos empreendimentos empresariais não cause perdas aos quadros de pesquisadores das universidades.

Uma questão que tem sido vista com bons olhos junto à comunidade acadêmica é a participação de alunos de graduação e pós-graduação na criação de empresas a partir de resultados de pesquisa. Entretanto, para que isso se torne factível, é necessário capacitar esses alunos, oferecendo-lhes disciplinas que os instruam gerencialmente, além de fornecer ferramentas para a busca de recursos financeiros (Torkomian, 1997).

Através de um estudo de caso realizado em uma universidade pública brasileira - a Universidade Federal de São Carlos - Azevedo (2005) fez as seguintes considerações sobre a criação de empresas a partir de resultados de pesquisas:

1. Para o surgimento dos spin-offs acadêmicos é necessário que haja a presença de entidades produtoras de conhecimento, de pesquisadores com perfil empreendedor, de organizações de apoio e de programas de financiamento.

2. As responsabilidades e os riscos inerentes à criação de empresas fica a cargo dos pesquisadores e alunos que tomaram estas iniciativas. A universidade não faz nenhum tipo de investimento, além do conhecimento transmitido a esses empreendedores.

3. A criação de spin-offs beneficia toda a sociedade, ao oferecer-lhe produtos e serviços cujo conhecimento e tecnologia são frutos de pesquisas realizadas nas universidades. 
4. As empresas criadas geram empregos, onde prevalece o alto nível de qualificação. Em decorrência do ramo de atividade dessas firmas, geralmente elas empregam pouca mão-de-obra.

5. As relações entre as universidades e os spin-offs surgidos delas são intensas e tendem a aumentar com a evolução das empresas.

6. Geralmente os pesquisadores, apesar de formarem uma empresa, mantêm seus vínculos empregatícios com a universidade. Desta forma, a ligação das empresas com as universidades tende a permanecer forte ao longo do tempo.

7. A satisfação em colocar à disposição da sociedade os resultados de suas pesquisas e a possibilidade de obter bons retornos financeiros são as principais motivações para a criação de empresas pelos pesquisadores.

8. Há poucos incentivos no meio acadêmico para a formação de spin-offs, seja pelo excesso de burocracia, como também pela falta de uma legislação mais clara quanto à propriedade intelectual.

9. Geralmente, para se constituírem, os spin-offs necessitam de suporte. Isso pode ocorrer via instalação em uma incubadora ou por meio de programas públicos de incentivos.

10. Os pesquisadores consideram que é importante haver programas no meio acadêmico que incentivem o empreendedorismo. Entretanto se observa que há poucas ações nesse sentido.

11. As principais barreiras encontradas são: a necessidade de um contínuo desenvolvimento tecnológico, a falta de capacitação gerencial por parte dos pesquisadores que decidem criar uma empresa, e as pressões sofridas no ambiente acadêmico em decorrência da cultura dessa instituição.

\section{Metodologia}

O presente estudo constitui uma pesquisa descritiva, pois analisa fatos sem manipulá-los; e é um estudo exploratório, já que há pouco conhecimento sobre spin-offs acadêmicos no Brasil.

O objetivo principal deste trabalho é caracterizar os spin-offs acadêmicos do Brasil, mas para isso será necessário atingir os seguintes objetivos secundários: 
. obter a descrição da firma;

. verificar quais são os problemas enfrentados pelos spin-offs acadêmicos;

. verificar qual é o tipo de relação que os spin-offs mantêm com as organizações de origem;

- verificar os fatores motivadores e inibidores do surgimento dos spin-offs acadêmicos.

Para atingir os objetivos apresentados foi feita uma pesquisa de campo por meio de questionários estruturados enviados via $e$-mail a empresas que poderiam ter surgido de pesquisas desenvolvidas em treze universidades brasileiras: Universidade de São Paulo [USP]; Universidade Estadual de Campinas [UNICAMP]; Universidade Federal do Rio de Janeiro [UFRJ]; Universidade Federal do Paraná [UFPR]; Universidade Federal de Minas Gerais [UFMG]; Universidade Federal do Pará [UFPA]; Universidade Federal do Ceará [UFC]; Universidade Federal de Pernambuco [UFPE]; Universidade Federal de Santa Catarina [UFSC]; Universidade Federal do Rio Grande do Sul [UFRGS]; Universidade Federal de São Carlos [UFSCar]; Pontifícia Universidade Católica do Rio de Janeiro [PUC-RIO]; Universidade de Brasília [UNB]. Para a realização da pesquisa, a definição de spin-offs acadêmicos apresentada às empresas teve que ser simples e direta, pois as pesquisadoras não poderiam ser contatadas para tirar possíveis dúvidas a respeito do questionário.

Portanto, estabeleceu-se que spin-offs acadêmicos são empresas que surgiram a partir de resultados pesquisas desenvolvidas em universidades. Esta definição não restringe os spin-offs às empresas que tenham acadêmicos com sócios e não é tão abrangente para incluir as empresas que foram criadas a partir do conhecimento adquirido na universidade, sem a execução de pesquisas.

Como foi apresentado anteriormente, a meta inicial da pesquisa de campo era obter informações sobre spin-offs de treze universidades brasileiras. Com o intuito de atingir esta meta foram enviados questionários para empresas que estavam incubadas ou associadas às incubadoras destas universidades e em alguns casos foram enviados para empresas que possuíam estas mesmas relações com incubadoras próximas às universidades. Vale ressaltar que o envio de questionários, como método de coleta de dados, foi utilizado porque os objetos de pesquisa estão dispersos pelo Brasil.

Inicialmente foram enviadas 547 mensagens eletrônicas; destas somente 452 puderam ser considerados válidas, pois 95 voltaram, devido a erros no endereço eletrônico ou porque a caixa postal estava cheia. 
Após a primeira chamada, foram respondidos apenas 30 questionários, gerando a necessidade de fazer a segunda chamada. Nesta etapa foram reenviadas 422 mensagens eletrônicas e obteve-se a resposta de 57 empresas, perfazendo um total de 87 questionários respondidos.

Considerando que o total de e-mails válidos foi de 452 e que os respondidos totalizaram 87 , obtém-se que a taxa de resposta foi de $19,25 \%$.

Entretanto, ao realizar a análise dos dados, verificou-se que do total de questionários respondidos 51 não eram spin-offs acadêmicos, ou seja, apenas 36 afirmaram ser spin-offs.

Além disso, três empresas que deram uma afirmativa como resposta não puderam ser incluídas na amostra pesquisada, pois eram de instituições acadêmicas que não faziam parte da meta inicial.

Portanto, as informações apresentadas ao longo do próximo tópico são referentes a 33 spin-offs oriundos de 9 universidades brasileiras.

\section{Apresentação e Análise dos Resultados}

\section{Caracterização das Empresas e dos Sócios}

\section{Empresa: Localização e Universidade de Origem}

Um fator que acaba por delimitar algumas características de todas as empresas é o local onde elas se localizam, pois geralmente é nele que elas buscarão a mãode-obra, a tecnologia e o aporte financeiro inicial. No caso dos spin-offs acadêmicos, a universidade de origem também tem importância significativa, isto porque ela provê boa parte do conhecimento científico e tecnológico utilizado pelas empresas como um gatilho inicial de suas atividades.

Nesta pesquisa buscou-se analisar spin-offs acadêmicos de diversas partes do país, para que fosse possível elaborar um panorama, mesmo que parcial, do cenário brasileiro.

Entretanto, devido às limitações da pesquisa, não foi possível abarcar empresas de todas as regiões do Brasil, nem mesmo manter a uniformidade na quantidade de empresas analisadas de cada região.

Conforme pode ser observado na Tabela 1, a maior parte dos spin-offs estudados, cerca de $61 \%$, situa-se na região Sudeste, e o restante localiza-se na 
região Sul, Centro-Oeste e Nordeste, representando respectivamente 24,2\%, 9,1\% e $6,1 \%$ da amostra.

\section{Tabela 1: Localização dos Spin-offs Acadêmicos}

\begin{tabular}{|l|r|r|}
\hline Região (i) & \multicolumn{1}{|c|}{ fi } & \multicolumn{2}{|c|}{ pi(\%) } \\
\hline Sudeste & 20 & 60,6 \\
\hline Sul & 8 & 24,2 \\
\hline Nordeste & 3 & 9,1 \\
\hline Centro-Oeste & 2 & 6,1 \\
\hline Total & $\mathbf{3 3}$ & $\mathbf{1 0 0 , 0}$ \\
\hline
\end{tabular}

Inicialmente havia a intenção de analisar spin-offs surgidos de 13 universidades de destaque no cenário nacional e até mesmo internacional. Entretanto não foram obtidos questionários de duas instituições acadêmicas e de outras duas os questionários apontavam que as empresas, apesar de possuírem algum tipo de ligação com as universidades, não eram spin-offs acadêmicos.

A distribuição das empresas entre as nove instituições restantes segue como se mostra na Tabela 2, onde é possível notar que as quantidades de spin-offs da USP, UNICAMP e UFSC são as mais representativas da amostra. Observando a tabela, verifica-se que estas universidades são representadas por $21,2 \%$ da amostra, cada uma. E que as outras são representadas por menos de $40 \%$ da amostra.

Tabela 2: Universidade de Origem

\begin{tabular}{|l|r|r|}
\hline Universidade (i) & \multicolumn{1}{|c|}{ fi } & \multicolumn{2}{|c|}{ pi(\%) } \\
\hline UFSC & 7 & 21,2 \\
\hline UNICAMP & 7 & 21,2 \\
\hline USP & 7 & 21,2 \\
\hline UFC & 3 & 9,1 \\
\hline UFRJ & 3 & 9,1 \\
\hline PUC & 2 & 6,1 \\
\hline UNB & 2 & 6,1 \\
\hline UFPR & 1 & 3,0 \\
\hline UFSCar & 1 & 3,0 \\
\hline Total & $\mathbf{3 3}$ & $\mathbf{1 0 0 , 0}$ \\
\hline
\end{tabular}

\section{Empresa Idade}

O tempo de existência de uma empresa é um dado relevante, pois geralmente ele influencia as outras características da empresa como, por exemplo, o tamanho e o mercado de atuação. 
A amostra pesquisada registra maior incidência de empresas com idades inferiores a 5 anos. Cerca de $61 \%$ dos spin-offs estudados foram criados a partir de 2000, conforme pode ser observado na Tabela 3.

\section{Tabela 3: Ano de Fundação da Empresa}

\begin{tabular}{|l|r|r|}
\hline Fundação (i) & \multicolumn{1}{|c|}{ Fi } & \multicolumn{2}{|c|}{ pi(\%) } \\
\hline 1985 a 1990 & 2 & 6,1 \\
\hline 1991 a 1995 & 4 & 12,1 \\
\hline 1996 a 2000 & 7 & 21,2 \\
\hline 2001 a 2005 & 20 & 60,6 \\
\hline Total & $\mathbf{3 3}$ & $\mathbf{1 0 0 , 0}$ \\
\hline
\end{tabular}

A baixa idade das empresas da amostra pode estar relacionada a dois fatores: (a) as empresas foram buscadas em incubadoras; e (b) o processo de formação de spin-offs acadêmicos no Brasil é recente.

Não existe no país uma base de dados que identifique quais empresas são spinoffs e onde foram desenvolvidas as pesquisas que deram origem a elas. Em decorrência deste fato, fez-se necessário buscar as empresas em locais próximos às universidades; e isto deu-se através dos sites de incubadoras situadas dentro das instituições acadêmicas ou próximas a elas.

Nos sites das universidades há listagens de empresas incubadas, graduadas ou associadas às incubadoras. Crê-se que a maioria das empresas que responderam o questionário pertenciam à primeira categoria e que, portanto, eram muito jovens.

Por outro lado, deve-se considerar o fato de que por muito tempo a legislação brasileira e a cultura acadêmica do país atrapalharam e até mesmo impediram a criação de empresas, a partir de resultados de pesquisas desenvolvidas em universidades, o que já vinha acontecendo há décadas nos Estados Unidos e em alguns países da Europa.

Acredita-se que isto está diretamente relacionado com o tempo de existência destas empresas, fazendo com que a maioria dos spin-offs acadêmicos da amostra tenha menos de cinco anos.

\section{Empresa Tamanho}

Quando é feita uma análise do tamanho das empresas pesquisadas, percebe-se que a classificação varia conforme mudam os parâmetros. Seguindo o critério do SEBRAE, todas as empresas são consideradas micro e pequenas (Tabela 4), já pelo critério do Estatuto das Micro e Pequenas Empresas (Lei Federal 9.841/99 
atualizada pelo decreto 5.028/04), 12,1\% são classificadas como média ou grande (Tabela 5).

\section{Tabela 4: Tamanho dos Spin-offs Acadêmicos - SEBRAE}

\begin{tabular}{|l|r|r|}
\hline Tamanho (i) & \multicolumn{1}{|c|}{ fi } & \multicolumn{2}{|c|}{ pi(\%) } \\
\hline Micro & 20 & 60,6 \\
\hline Pequena & 11 & 33,3 \\
\hline Não responderam & 2 & 6,1 \\
\hline Total & $\mathbf{3 3}$ & $\mathbf{1 0 0 , 0}$ \\
\hline
\end{tabular}

\section{Tabela 5: Tamanho dos Spin-offs Acadêmicos - Est. das Micro e Pequenas Empresas}

\begin{tabular}{|l|r|r|}
\hline Tamanho (i) & \multicolumn{1}{|c|}{ fi } & \multicolumn{1}{|c|}{ pi(\%) } \\
\hline Micro & 21 & 63,7 \\
\hline Pequena & 4 & 12,1 \\
\hline Média ou grande & 4 & 12,1 \\
\hline Não responderam & 4 & 12,1 \\
\hline Total & $\mathbf{3 3}$ & $\mathbf{1 0 0 , 0}$ \\
\hline
\end{tabular}

Para o SEBRAE, o tamanho de uma empresa é avaliado pelo número de empregados que ela possui e pelo tipo de empresa que ela é (comércio ou indústria). Uma característica positiva deste critério é que as informações são facilmente obtidas e geralmente as empresas não passam dados distorcidos, já que a divulgação do número de empregados não causa nenhum impacto negativo sobre a empresa.

Já a classificação das empresas pelo critério do Estatuto das Micro e Pequenas Empresas possui algumas dificuldades, pois este requer que o faturamento da empresa seja informado para que ela possa ser classificada. Entretanto há algumas empresas que temem informar o faturamento e outras que ao informar passam dados errôneos. Um ponto positivo deste mecanismo de classificação é que as empresas que atuam em áreas que demandam pouca mão-de-obra, mas que faturam muito e têm grande expressão no mercado podem ser categorizadas corretamente como médias e grandes empresas.

Estas diferenças entre os critérios implicam políticas públicas que se conformam melhor a cada empresa, porque, apesar de possuírem um número de funcionários que as classificam de uma maneira e que, portanto, segundo as pesquisas demandam determinado conjunto de ações do Estado, através de outros requisitos, como o faturamento, nota-se que suas necessidades podem estar além daquelas apresentadas em um primeiro momento. 


\section{Empresa Área de Atuação}

A área em que atua a empresa serve como indicador de várias características da empresa, como, por exemplo, mercado alvo, necessidade de investimento em tecnologia e necessidade de mão-de-obra.

No caso da amostra pesquisada, verifica-se que a maior parte atua em áreas tecnológicas, mas que se diferenciam, quando pensadas em relação à matriz tecnológica utilizada em cada uma.

Além disso, observa-se que algumas dessas áreas são mais demandantes de investimento e outras mais dependentes de mão-de-obra. As 6 principais áreas em que as empresas analisadas se enquadram são: eletrônica, tecnologia da informação, ciência dos alimentos, tecnologia ambiental, biotecnologia e óptica.

\section{Empresa Escolaridade dos Funcionários}

A qualificação do empregado envolvido nas atividades da empresa está diretamente relacionada com a área em que ela atua e com a qualidade do produto ou serviço que espera fornecer ao cliente.

Quando a empresa atua em uma área mais tecnológica, exige-se que ela seja capaz de acompanhar o ritmo das transformações ocorridas no ambiente em que está inserta, pois só desta maneira ela será capaz de perpetuar-se ao longo do tempo.

Além disso, quanto mais inovativo é o ambiente concorrencial onde o spin-off atua, maior é a formação exigida dos empregados. De acordo com a Tabela 6, os funcionários de 63,6\% das empresas pesquisadas têm pelo menos o ensino superior, indicando a alta qualificação da mão-de-obra empregada por elas.

Tabela 6: Escolaridade dos Funcionários

\begin{tabular}{|l|r|r|}
\hline Nível de escolaridade (i) & \multicolumn{1}{|c|}{ fi } & \multicolumn{2}{|c|}{ pi(\%) } \\
\hline Ensino Superior & 16 & 48,5 \\
\hline Ensino Médio & 5 & 15,2 \\
\hline Mestrado & 4 & 12,1 \\
\hline Ensino Fundamental & 3 & 9,1 \\
\hline Doutorado & 1 & 3,0 \\
\hline Não responderam & 4 & 12,1 \\
\hline Total & $\mathbf{3 3}$ & $\mathbf{1 0 0 , 0}$ \\
\hline
\end{tabular}




\section{Empresa Investimento em Tecnologia}

A constante transformação tecnológica e, conseqüentemente, o rápido obsoletismo a que estão sujeitos os spin-offs acadêmicos que atuam em áreas consideradas de alta tecnologia, impõe que estes permanentemente invistam em tecnologia.

Isso pode ser verificado a partir dos dados apresentados na Tabela 7, onde observa-se que $66,8 \%$ da amostra realizaram algum tipo de investimento em tecnologia em 2004 e que, em média, estas empresas investiram 27,9\% do faturamento.

Tabela 7: Investimento em Tecnologia

\begin{tabular}{|l|r|r|}
\hline \multicolumn{1}{|c|}{ Investimento } & \multicolumn{1}{|c|}{ fi } & \multicolumn{1}{c|}{ pi(\%) } \\
\hline $0 \%$ & 3 & 9,1 \\
\hline $1 \%$ a $20 \%$ & 10 & 30,3 \\
\hline $21 \%$ a $40 \%$ & 6 & 18,2 \\
\hline $41 \%$ a $60 \%$ & 4 & 12,1 \\
\hline $61 \%$ a $80 \%$ & 1 & 3,0 \\
\hline $81 \%$ a $100 \%$ & 1 & 3,0 \\
\hline Não responderam & 8 & 24,2 \\
\hline Total & $\mathbf{3 3}$ & $\mathbf{1 0 0 , 0}$ \\
\hline
\end{tabular}

\section{Empresa Patentes}

Possuir patente própria ou obter o licenciamento de uma permite às empresas se protegerem contra eventuais cópias de produtos (serviços) ou processos, principalmente quando estes são inovativos e lucrativos.

Entretanto, a maioria dos spin-offs estudados não possui patentes (próprias ou licenciadas), perfazendo um total de $60,6 \%$ da amostra (Tabela 8). Isto pode ser decorrente da burocracia existente no país para conseguir depositar uma patente ou devido à inexperiência das universidades brasileiras com o processo de patenteamento dos resultados de pesquisa.

Acredita-se que, por serem originadas de resultados de pesquisas, estas empresas oferecem ao mercado um produto (serviço) altamente inovativo e que, portanto, precisaria ser protegido. 


\section{Tabela 8: Existência de Patentes Depositadas}

\begin{tabular}{|l|r|r|}
\hline Categoria (i) & \multicolumn{1}{|c|}{ fi } & \multicolumn{2}{|c|}{ pi(\%) } \\
\hline Não & 20 & 60,6 \\
\hline Sim & 13 & 39,4 \\
\hline Total & $\mathbf{3 3}$ & $\mathbf{1 0 0 , 0}$ \\
\hline
\end{tabular}

Outro fator importante é que, mesmo sendo originárias do meio acadêmico, as empresas com patentes depositadas, as têm por meios próprios, isto é, em apenas $23,1 \%$ das empresas, as patentes têm a origem nas universidades (Tabela 9).

Esperava-se que entre os spin-offs acadêmicos a porcentagem de patentes depositadas, pertencentes às universidades, fosse maior, já que a maioria deles surgiu de universidades públicas e, portanto, utilizou recursos públicos.

Tabela 9: Origem das Patentes

\begin{tabular}{|l|r|r|}
\hline Origem das patentes (i) & \multicolumn{1}{|c|}{ fi } & \multicolumn{1}{|c|}{ pi(\%) } \\
\hline Próprias & 10 & 76,9 \\
\hline Universidades & 3 & 23,1 \\
\hline Outras instituições & 0 & 0,0 \\
\hline Total & $\mathbf{1 3}$ & $\mathbf{1 0 0 , 0}$ \\
\hline
\end{tabular}

\section{Empresa Mercado deAtuação}

Ao serem questionadas quanto ao principal mercado de atuação da empresa, $54,5 \%$ da amostra responderam que era o nacional. E para o internacional e o regional obteve-se a resposta de $12,1 \%$ e $27,3 \%$, respectivamente (Tabela 10).

Um ponto positivo, observado a partir destes dados, é o impacto em âmbito nacional da pesquisa desenvolvida na universidade, pois os produtos (serviços) são ofertados para todo o país. Além disso, mesmo em proporção menor, algumas empresas exportam seus produtos, gerando divisas para o Brasil.

Acredita-se que a maior parte da carteira de produtos destes spin-offs sirva como substitutos aos importados, e que as empresas que atuam regionalmente tendem a expandir suas atuações para o mercado nacional e posteriormente $o$ internacional. 
Tabela 10: Mercado de Atuação

\begin{tabular}{|l|r|r|}
\hline Mercado (i) & \multicolumn{1}{|c|}{ fi } & \multicolumn{1}{|c|}{ pi(\%) } \\
\hline Nacional & 18 & 54,5 \\
\hline Regional & 9 & 27,3 \\
\hline Internacional & 4 & 12,1 \\
\hline Não responderam & 2 & 6,1 \\
\hline Total & $\mathbf{3 3}$ & $\mathbf{1 0 0 , 0}$ \\
\hline
\end{tabular}

\section{Empresa Fontes de Recursos Financeiros}

Para que a empresa se solidifique no mercado e se perpetue ao longo do tempo, é necessário que haja recursos financeiros que permitam investir em tecnologia e fidelizar o mercado.

Segundo os dados apresentados na Tabela $11,84,8 \%$ da amostra utilizou e utiliza recursos próprios. Entretanto ressalta-se que a importância do governo é significativa, pois muitas empresas utilizaram o dinheiro público por meio do CNPq, da FINEP e das Fundações de apoio à pesquisa.

Vale destacar que no Brasil, diferentemente do que ocorre em outros países, pouco ou nenhum recurso é investido pelos capitalistas de risco nas empresas start-ups. Isto pôde ser verificado nas empresas estudadas, pois nenhum dos spin-offs acadêmicos recebeu algum tipo de apoio financeiro destas instituições.

\section{Tabela 11: Fontes de Financiamento}

\begin{tabular}{|c|c|c|}
\hline Fontes (i) & fi & pi(\%) \\
\hline Próprios & 28 & 84,8 \\
\hline $\begin{array}{l}\text { Fundação de apoio à pesquisa: } \\
\text { Fapesp, Faperj, Fapdf etc. }\end{array}$ & 13 & 39,4 \\
\hline $\mathrm{CNPq}$ & 11 & 33,3 \\
\hline FINEP & 7 & 21,2 \\
\hline Bancos Comuns & 3 & 9,1 \\
\hline BNDES & 0 & 0,0 \\
\hline Capital de Risco & 0 & 0,0 \\
\hline Outros & 3 & 9,1 \\
\hline Não responderam & 2 & 6,1 \\
\hline
\end{tabular}




\section{Sócios Características Gerais}

Os resultados obtidos indicam que a maior parte das empresas pesquisadas possui três ou mais sócios, o que representa $60,6 \%$ da amostra (Tabela 12). Talvez este dado esteja relacionado com o fato de as pesquisas acadêmicas serem realizadas por um grupo de pesquisa.

Além disso, destaca-se que uma quantidade de sócios maior permite à empresa aumentar a capitalização inicial e possibilita a complementação de habilidades.

Tabela 12: Quantidade de Sócios

\begin{tabular}{|l|r|r|}
\hline Quantidade (i) & \multicolumn{1}{|c|}{ fi } & \multicolumn{1}{|c|}{ pi(\%) } \\
\hline Dois & 13 & 39,4 \\
\hline Três & 10 & 30,3 \\
\hline Quatro & 6 & 18,2 \\
\hline Cinco & 4 & 12,1 \\
\hline Total & $\mathbf{3 3}$ & $\mathbf{1 0 0 , 0}$ \\
\hline
\end{tabular}

Os dados apresentados sobre os sócios são referentes a um total de 100, que foi obtido multiplicando a primeira coluna da tabela anterior pela segunda e somando os valores.

Uma característica de destaque observada nos spin-offs acadêmicos é que eles são criados por pessoas de elevado nível educacional. Muitos, $45 \%$, têm pós graduação; $24 \%$ fizeram doutorado, $17 \%$ mestrado, $3 \%$ MBA e $1 \%$ pós-doutorado (Tabela 13). Esta alta qualificação dos sócios reforça a ligação existente entre eles e o meio acadêmico.

Tabela 13: Formação Acadêmica dos Sócios

\begin{tabular}{|l|r|r|}
\hline Formação (i) & \multicolumn{1}{|c|}{ fi } & \multicolumn{1}{|c|}{ pi(\%) } \\
\hline Ensino Superior & 31 & 31,0 \\
\hline Doutorado & 24 & 24,0 \\
\hline Mestrado & 17 & 17,0 \\
\hline Ensino Médio ou Técnico & 5 & 5,0 \\
\hline MBA & 3 & 3,0 \\
\hline Pós-doutorado & 1 & 1,0 \\
\hline Não responderam & 19 & 19,0 \\
\hline Total & $\mathbf{1 0 0}$ & $\mathbf{1 0 0 , 0}$ \\
\hline
\end{tabular}

Quanto à faixa etária dos sócios das empresas pesquisadas pode-se dizer que há equilíbrio. A Tabela 14 mostra que $30 \%$ dos sócios possuem entre 21 e 30 
anos, $30 \%$ entre 31 e 40, e $26 \%$ entre 41 e 50 anos. Os dados indicam que não são só os mais experientes em pesquisas que se aventuram em criar uma empresa, pois alguns sócios, no término da graduação, fundaram os spin-offs acadêmicos.

\section{Tabela 14: Faixa Etária dos Sócios}

\begin{tabular}{|l|r|r|}
\hline Idade (i) & \multicolumn{1}{|c|}{ fi } & \multicolumn{2}{|c|}{ pi(\%) } \\
\hline Até 20 & 1 & 1,0 \\
\hline 21 a 30 & 30 & 30,0 \\
\hline 31 a 40 & 30 & 30,0 \\
\hline 41 a 50 & 26 & 26,0 \\
\hline 51 a 60 & 5 & 5,0 \\
\hline 61 a 70 & 7 & 7,0 \\
\hline Não responderam & 1 & 1,0 \\
\hline Total & $\mathbf{1 0 0}$ & $\mathbf{1 0 0 , 0}$ \\
\hline
\end{tabular}

A maioria dos sócios (54\%) afirmou que possui entre 1 e 5 anos de experiência empresarial (Tabela 15). Acredita-se que isto ocorra porque a maior parte das empresas pesquisadas possui menos de 5 anos de existência.

É importante destacar que talvez os sócios não tenham compreendido que a experiência empresarial se referia tanto ao período anterior à formação do spinoff acadêmico quanto ao posterior. Este fato pôde ser observado porque 5 sócios afirmaram não possuir nenhuma experiência em empresas, apesar de possuírem no mínimo o tempo de existência da empresa como experiência.

Ainda de acordo com os dados obtidos, 41 sócios pesquisados possuem apenas experiência empresarial por meio dos spin-offs acadêmicos, o que representa $41 \%$ da amostra.

\section{Tabela 15: Tempo de Experiência Empresarial}

\begin{tabular}{|l|r|r|}
\hline \multicolumn{1}{|c|}{ Experiência empresarial (anos) } & \multicolumn{1}{c|}{ fi } & \multicolumn{1}{c|}{ pi(\%) } \\
\hline Nenhuma & 5 & 5,0 \\
\hline 1 a 5 & 54 & 54,0 \\
\hline 6 a 10 & 20 & 20,0 \\
\hline 11 a 15 & 6 & 6,0 \\
\hline 16 a 20 & 8 & 8,0 \\
\hline 21 a 25 & 2 & 2,0 \\
\hline acima de 25 & 4 & 4,0 \\
\hline Não responderam & 1 & 1,0 \\
\hline Total & $\mathbf{1 0 0}$ & $\mathbf{1 0 0 , 0}$ \\
\hline
\end{tabular}


Reforçando a forte ligação dos sócios dos spin-offs com o meio acadêmico, a Tabela 16 mostra que $36 \%$ têm mais de seis anos de experiência como pesquisador ou como professor e que apenas $14 \%$ não possui nenhuma experiência deste tipo na academia.

Tabela 16: Tempo de Experiência Acadêmica

\begin{tabular}{|l|r|r|}
\hline \multicolumn{1}{|c|}{ Experiência acadêmica (anos) } & \multicolumn{1}{c|}{ fi } & \multicolumn{1}{c|}{ pi(\%) } \\
\hline Nenhuma & 14 & 14,0 \\
\hline 1 a 5 & 32 & 32,0 \\
\hline 6 a 10 & 11 & 11,0 \\
\hline 11 a 15 & 11 & 11,0 \\
\hline 16 a 20 & 8 & 8,0 \\
\hline acima de 20 & 6 & 6,0 \\
\hline Não responderam & 18 & 18,0 \\
\hline Total & $\mathbf{1 0 0}$ & $\mathbf{1 0 0 , 0}$ \\
\hline
\end{tabular}

\section{Cooperação Universidade-Empresa}

Segundo os dados apresentados na Tabela 2, quase 94\% das empresas pesquisadas vêm de universidades públicas. Portanto esperava-se que houvesse amplo apoio destas instituições no processo de formação dos spin-offs acadêmicos, já que estes criam novos empregos, geram divisas ao Estado e, consequientemente, dinamizam a economia local.

Entretanto a Tabela 17 aponta que menos de $40 \%$ da amostra receberam algum tipo de apoio das universidades. Além disso, a maioria das empresas que recebeu apoio afirmou que estes eram referentes a infra-estrutura física e cursos. Crê-se que isto esteja diretamente relacionado com o fato de os questionários terem sido enviados a empresas que tinham algum tipo de ligação com incubadoras e que, portanto, lhes ofereciam cursos de aprimoramento e espaço físico.

É importante destacar que duas empresas, que afirmaram não ter recebido nenhum tipo de apoio da universidade, se localizam dentro delas.

Tabela 17: Apoio Recebido das Universidades de Origem

\begin{tabular}{|l|r|r|}
\hline Apoio (i) & \multicolumn{1}{|c|}{ fi } & \multicolumn{2}{|c|}{ pi(\%) } \\
\hline Não & 18 & 54,5 \\
\hline Sim & 13 & 39,4 \\
\hline Não responderam & 2 & 6,1 \\
\hline Total & $\mathbf{3 3}$ & $\mathbf{1 0 0 , 0}$ \\
\hline
\end{tabular}


Apesar de a maioria das empresas não ter recebido nenhum tipo de apoio, 69,6\% dos spin-offs localizam-se próximos às universidades e distam delas não mais de 5 quilômetros. Além disso, 24,2\% da amostra situa-se nas universidades, provavelmente dentro das incubadoras.

Estes dados podem ser vistos na Tabela 18 e sugerem que a maioria dos spinoffs se localiza próxima às universidades, porque estas são fontes contínuas de informação e devido à relação existente entre os sócios das empresas e as instituições acadêmicas. Além disso, como dito anteriormente, as universidades que possuem incubadoras oferecem incentivos às empresas.

\section{Tabela 18: Distância entre a Universidade e o Spin-off Acadêmico}

\begin{tabular}{|l|r|r|}
\hline Distância & \multicolumn{1}{|c|}{ fi } & \multicolumn{1}{|c|}{ pi(\%) } \\
\hline Dentro da universidade & 8 & 24,2 \\
\hline 1 a $5 \mathrm{~km}$ & 15 & 45,4 \\
\hline 6 a $10 \mathrm{~km}$ & 2 & 6,1 \\
\hline 11 a $15 \mathrm{~km}$ & 2 & 6,1 \\
\hline 16 a $20 \mathrm{~km}$ & 2 & 6,1 \\
\hline acima de 20 & 3 & 9,1 \\
\hline Não responderam & 1 & 3,0 \\
\hline Total & $\mathbf{3 3}$ & $\mathbf{1 0 0 , 0}$ \\
\hline
\end{tabular}

Outra informação importante é que a maioria das empresas estudadas mantém ações de cooperação com a universidade da qual ela se originou. Conforme a Tabela 19,54,5\% realizam pesquisa em cooperação; 42,4\% utilizam os laboratórios e serviços técnicos; e $36,4 \%$ possuem relações informais com integrantes do meio acadêmico.

Entre as empresas que realizam pesquisa em cooperação, estão dois dos três spin-offs que possuem patentes depositadas, cuja propriedade é da universidade de origem.

Já entre os que utilizam os laboratórios e serviços técnicos das universidades, quatro estão localizadas dentro das incubadoras das universidades. E nove empresas que possuem relações informais com os integrantes do meio acadêmico distam menos de 5 quilômetros das universidades. 


\section{Tabela 19: Tipos de Cooperação entre os Spin-offs e o Meio Acadêmico}

\begin{tabular}{|l|r|r|}
\hline \multicolumn{1}{|c|}{ Tipo de cooperação } & \multicolumn{1}{c|}{ fi } & \multicolumn{1}{c|}{ pi(\%) } \\
\hline Pesquisa em cooperação & 18 & 54,5 \\
\hline $\begin{array}{l}\text { Utilização dos laboratórios e serviços } \\
\text { técnicos }\end{array}$ & 14 & 42,4 \\
\hline Relações informais & 12 & 36,4 \\
\hline Consultoria & 6 & 18,2 \\
\hline Contratação de recursos humanos & 5 & 15,2 \\
\hline Nenhuma & 5 & 15,2 \\
\hline Não responderam & 1 & 3,0 \\
\hline
\end{tabular}

Observação: havia a possibilidade de serem escolhidas até 3 alternativas para este item, por isso a porcentagem de cada opção é calculada individualmente.

\section{Criação de Spin-offs Acadêmicos: Motivações e Dificuldades Antes e Pós Fundação}

Os dados mostram que $84,8 \%$ dos spin-offs acadêmicos foram criados a partir da identificação de oportunidades de mercado (Tabela 20). Isso indica que as pesquisas que deram origem a elas tinham um forte aspecto prático e possuíam valor de mercado para serem transferidas. Corroborando esta afirmação, 48,5\% das empresas estudadas apontaram que foram criadas devido à necessidade de aplicar o conhecimento em questões práticas.

Um fato a ser destacado é que apenas $6,1 \%$ das empresas apontaram a necessidade de interação com o mercado para enriquecer a atividade acadêmica como uma das motivações para a criação dos spin-offs. Este fato merece destaque, porque muitos que defendem a utilização do dinheiro público em pesquisas que possam dar origem a empresas usam este argumento.

As razão financeiras também merecem destaque entre as motivações, pois foram citadas por um terço da amostra. Estas razões podem englobar tanto a necessidade de aumentar os rendimentos quanto a fuga ao desemprego.

A necessidade de obter retorno sobre a qualidade de trabalho realizado e a aversão à burocracia existente nas universidades para atender clientes externos são fatores do meio acadêmico que fizeram com que algumas empresas fossem criadas. 
Tabela 20: Fatores que Motivaram o Surgimento dos Spin-offs Acadêmicos

\begin{tabular}{|c|c|c|}
\hline Motivações (i) & fi & pi $(\%)$ \\
\hline Identificação de oportunidades de mercado & 28 & 84,8 \\
\hline $\begin{array}{l}\text { Necessidade de aplicar o conhecimento acadêmico em } \\
\text { questões práticas }\end{array}$ & 16 & 48,5 \\
\hline Razões financeiras & 11 & 33,3 \\
\hline Obtenção de sucesso pessoal & 7 & 21,2 \\
\hline $\begin{array}{l}\text { Necessidade de obter retorno sobre a qualidade do trabalho } \\
\text { realizado }\end{array}$ & 6 & 18,2 \\
\hline Necessidade de ser mais independente & 5 & 15,2 \\
\hline $\begin{array}{l}\text { Necessidade de explorar a experiência (não necessariamente } \\
\text { acadêmica) }\end{array}$ & 3 & 9,1 \\
\hline $\begin{array}{l}\text { Necessidade de interação com o mercado para enriquecer a } \\
\text { atividade acadêmica }\end{array}$ & 2 & 6,1 \\
\hline $\begin{array}{l}\text { Aversão à burocracia existente nas universidades para atender } \\
\text { clientes externos }\end{array}$ & 1 & 3,0 \\
\hline Outros & 2 & 6,1 \\
\hline Não responderam & 3 & 9,1 \\
\hline
\end{tabular}

Observação: havia a possibilidade de serem escolhidas até 3 alternativas para este item, por isso a porcentagem de cada opção é calculada individualmente.

Com exceção da falta de capacitação gerencial, da aversão ao risco e da estabilidade no emprego, todas as principais barreiras citadas são referentes a fatores ambientais. Isto mostra que para diminuir as barreiras que existem para a formação de um spin-off acadêmico é necessária a ação do Estado mediante programas governamentais.

Cerca de $52 \%$ da amostra respondeu que a principal barreira para o surgimento das empresas foi a falta de capacitação gerencial (Tabela 21). Acredita-se que isto seja resultado do meio em que os sócios estavam insertos, isto é o meio acadêmico, no qual por muito tempo não foram transmitidos aos seus integrantes conhecimentos administrativos que os capacitassem a gerir uma empresa.

A reação dos colegas de trabalho e as restrições impostas pela universidade são barreiras impostas pelo ambiente da universidade; apesar do baixo peso atribuídas a elas, é importante que políticas institucionais sejam elaboradas, para que as instituições acadêmicas possam contribuir mais efetivamente com o processo de formação dos spin-offs.

As outras barreiras referem-se a fatores do macroambiente brasileiro, que dificultam o surgimento de qualquer tipo de empresa, como, por exemplo, a taxação excessiva e a instabilidade econômica do país, citadas respectivamente por $51,5 \%$ e $21,2 \%$ da amostra. 
Tabela 21: Fatores que Dificultaram o Surgimento dos Spin-offs Acadêmicos

\begin{tabular}{|l|r|r|}
\hline Barreiras (i) & \multicolumn{1}{|c|}{ fi } & \multicolumn{1}{|c|}{ pi(\%) } \\
\hline Falta de capacitação gerencial & 17 & 51,5 \\
\hline Taxação excessiva & 17 & 51,5 \\
\hline Falta de recursos financeiros & 15 & 45,5 \\
\hline Burocracia excessiva para criar uma empresa & 8 & 24,2 \\
\hline Falta de apoio público & 7 & 21,2 \\
\hline Instabilidade econômica do país & 7 & 21,2 \\
\hline Reação dos colegas de trabalho & 2 & 6,1 \\
\hline Restrições impostas pela universidade & 2 & 6,1 \\
\hline Aversão ao risco & 1 & 3,0 \\
\hline Estabilidade no emprego & 1 & 3,0 \\
\hline Outros & 3 & 9,1 \\
\hline Não responderam & 2 & 6,1 \\
\hline
\end{tabular}

Observação: havia a possibilidade de serem escolhidas até 3 alternativas para este item, por isso a porcentagem de cada opção é calculada individualmente.

Depois de constituídos, os spin-offs acadêmicos ainda enfrentam diversos problemas; o principal para $60,6 \%$ da amostra é a falta de recursos financeiros (Tabela 22). Talvez este problema esteja relacionado com os dados apresentados na Tabela 11, onde é possível verificar que geralmente os fundadores das empresas utilizam capital próprio e que não há investimento por parte dos capitalistas de risco.

Os outros problemas enfrentados pelas empresas são referentes à falta de capacitação gerencial dos sócios, representadas pelas dificuldades nas áreas de desenvolvimento, produção, distribuição, estimação da demanda etc.

Tabela 22: Problemas Enfrentados Depois do Estabelecimento dos Spin-offs

\begin{tabular}{|l|r|r|}
\hline Problemas (i) & \multicolumn{1}{|c|}{ fi } & \multicolumn{1}{|c|}{ pi(\%) } \\
\hline Falta de recursos financeiros & 20 & 60,6 \\
\hline Questões comerciais & 17 & 51,5 \\
\hline Problemas técnicos no desenvolvimento e produção & 10 & 30,3 \\
\hline Uma estimação errada da demanda de mercado & 6 & 18,2 \\
\hline Problemas entre os proprietários & 6 & 18,2 \\
\hline Problemas na administração de recursos humanos & 5 & 15,2 \\
\hline Dificuldade com a distribuição & 3 & 9,1 \\
\hline $\begin{array}{l}\text { Problemas de relacionamento com o grupo de pesquisa que } \\
\text { obteve o resultado que deu origem a empresa }\end{array}$ & 1 & 3,0 \\
\hline Problemas com patentes & 1 & 3,0 \\
\hline Problemas contratuais & 0 & 0,0 \\
\hline Outros & 6 & 18,2 \\
\hline Não responderam & 1 & 3,0 \\
\hline
\end{tabular}

Observação: havia a possibilidade de serem escolhidas até 3 alternativas para este item, por isso a porcentagem de cada opção é calculada individualmente. 


\section{ConClusões}

De forma resumida, pode-se dizer que a maioria das empresas foi criada a partir de 2001 e que é caracterizada pela alta qualificação, tanto dos sócios quanto dos empregados, sendo suas áreas de atuação geralmente demandantes de alto potencial tecnológico.

Além disso, a maior parte das empresas é de microporte, atua nacionalmente e é formada por mais de dois sócios. Uma característica importante dos spin-offs estudados é que, apesar de serem oriundos de instituições acadêmicas e de terem desenvolvido nelas pesquisas que deram origem às empresas, poucas possuem patentes próprias ou licenciadas pelas universidades.

Com relação ao envolvimento das universidades com estas empresas, percebe-se que ele permanece forte, apesar de a maioria não ter recebido apoio para a fundação dos spin-offs. Observa-se também que mais da metade das empresas se situam próximas às universidades de origem e que apenas 15,2\% afirmaram não realizar nenhum tipo de cooperação com as instituições acadêmicas.

Quanto à principal motivação para a criação das empresas, destaca-se a identificação de oportunidades de mercado. Isto indica que as pesquisas tinham forte orientação prática e que os acadêmicos estavam capacitados a identificar estas oportunidades.

Entretanto percebe-se que, semelhante ao que ocorre com a maioria das empresas brasileiras, muitos spin-offs tiveram dificuldades com a falta de capacitação gerencial, e pela taxação excessiva e falta de recursos financeiros.

A Tabela 23 apresenta, de forma consolidada, os principais resultados obtidos com a pesquisa de campo. A primeira coluna apresenta as características analisadas; a segunda, os resultados; e a última, a base em que foram calculadas as porcentagem obtidas na coluna anterior. 


\section{Tabela 23: Consolidação dos Principais Resultados Obtidos na Pesquisa}

\begin{tabular}{|c|c|c|}
\hline Característica & Resultado & Observação \\
\hline Idade & $60,6 \%$ das empresas têm menos de 5 anos & Base $=33$ spin - offs \\
\hline Tamanho & 63,7\% são micro-empresas & Base $=33$ spin- offs \\
\hline $\begin{array}{l}\text { Escolaridade dos } \\
\text { funcionários }\end{array}$ & $\begin{array}{l}\text { A maioria dos funcionários de } 63,7 \% \text { da amostra têm pelo menos o } \\
\text { ensino superior }\end{array}$ & Base $=33$ spin-offs \\
\hline $\begin{array}{l}\text { Investimento em } \\
\text { tecnologia }\end{array}$ & $\begin{array}{l}\text { 66,8\% das empresas realizaram algum investimento em tecnologia } \\
\text { em } 2004 \text { e em média investiram } 27,9 \% \text { do faturamento }\end{array}$ & Base $=33$ spin-offs \\
\hline Patentes depositadas & $60,6 \%$ não têm patentes próprias ou de terceiros & Base $=33$ spin - offs \\
\hline Mercado de atuação & $\begin{array}{l}\text { O principal mercado de atuação para } 54,5 \% \text { das empresas é o } \\
\text { nacional }\end{array}$ & Base $=33$ spin-offs \\
\hline \multirow{2}{*}{$\begin{array}{l}\text { Fonte de recursos } \\
\text { financeiros }\end{array}$} & $84,8 \%$ utilizaram recursos próprios para financiar a empresa & $\begin{array}{l}\text { Base }=33 \text { spin-offs } \\
\text { Mais do que uma } \\
\text { opção poderiam } \\
\text { ser escolhidas }\end{array}$ \\
\hline & $\begin{array}{l}\text { Menos de } 50 \% \text { utilizaram o dinheiro público como fonte de } \\
\text { recursos financeiros }\end{array}$ & $\begin{array}{l}\text { Base=33 spin-offs } \\
\text { Mais do que uma } \\
\text { opção poderiam } \\
\text { ser escolhidas }\end{array}$ \\
\hline Quantidade de sócios & $60,6 \%$ das empresas possuem 3 ou mais sócios & Base $=100$ sócios \\
\hline $\begin{array}{l}\text { Experiência } \\
\text { empresarial }\end{array}$ & \begin{tabular}{|l}
$\begin{array}{l}\text { Apenas 5\% afirmaram não possuir nenhuma experiência } \\
\text { empresarial }\end{array}$ \\
\end{tabular} & Base $=100$ sócios \\
\hline $\begin{array}{l}\text { Experiência } \\
\text { acadêmica }\end{array}$ & $68 \%$ têm experiência acadêmica como pesquisador ou professor & Base $=100$ sócios \\
\hline $\begin{array}{l}\text { Apoio } \\
\text { universidade }\end{array}$ & $\begin{array}{l}54,5 \% \text { não receberam nenhum tipo de apoio da universidade para a } \\
\text { criação da empresa }\end{array}$ & Base $=33$ spin-offs \\
\hline $\begin{array}{l}\text { Distância } \\
\text { universidade }\end{array}$ & $69,6 \%$ distam até $5 \mathrm{~km}$ da universidade de origem & Base $=33$ spin-offs \\
\hline $\begin{array}{l}\text { Cooperação com a } \\
\text { universidade }\end{array}$ & $\begin{array}{l}\text { Apenas } 15,2 \% \text { não realizam atividades de cooperação com a } \\
\text { universidade de origem }\end{array}$ & $\begin{array}{l}\text { Base=33 spin-offs } \\
\text { Mais do que uma } \\
\text { opção poderiam } \\
\text { ser escolhidas }\end{array}$ \\
\hline $\begin{array}{l}\text { Principal motivação } \\
\text { para a criação da } \\
\text { empresa }\end{array}$ & $\begin{array}{l}\text { A identificação de oportunidade de mercado foi a principal } \\
\text { motivação para a criação de } 84,8 \% \text { das empresas }\end{array}$ & $\begin{array}{l}\text { Base=33 spin-offs } \\
\text { Mais do que uma } \\
\text { opção poderiam } \\
\text { ser escolhidas }\end{array}$ \\
\hline $\begin{array}{l}\text { Principal } \\
\text { para a criação da } \\
\text { empresa }\end{array}$ & $\begin{array}{l}\text { A falta de capacitação gerencial e a taxação excessiva foram as } \\
\text { principais dificuldades encontradas por } 51,5 \% \text { das empresas para o } \\
\text { seu estabelecimento }\end{array}$ & $\begin{array}{l}\text { Base }=33 \text { spin-offs } \\
\text { Mais do que uma } \\
\text { opção poderiam } \\
\text { ser escolhidas }\end{array}$ \\
\hline $\begin{array}{l}\text { Principal dificuldade } \\
\text { encontrada depois da } \\
\text { criação da empresa }\end{array}$ & $\begin{array}{l}\text { Para } 60,6 \% \text { a falta de recursos financeiros é o principal problema } \\
\text { enfrentado pela empresa depois de sua criação }\end{array}$ & $\begin{array}{l}\text { Base }=33 \text { spin-offs } \\
\text { Mais do que uma } \\
\text { opção poderiam } \\
\text { ser escolhidas }\end{array}$ \\
\hline
\end{tabular}

Cabe ressaltar que, apesar de este trabalho ter sido realizado por meio de um survey, suas conclusões não podem ser generalizadas, pois a amostra utilizada não era probabilística, isto porque, como foi dito anteriormente, este estudo é exploratório e, portanto, não havia nenhum banco de dados ou alguma outra referência que indicasse quais empresas spin-offs, para que elas pudessem ser analisadas.

A criação de empresas como mecanismo de transferência de tecnologia das universidades para a sociedade proporciona o seguinte: avanços tecnológicos, 
ampliação do aporte tecnológico do país; econômicos, geração de divisas ao Estado; sociais, criação de novos empregos; e acadêmicos, difusão do conhecimento para os países.

Entretanto, para que estes benefícios sejam gerados, é necessário que haja a ação conjunta de diversos atores: bancos, poder público, capitalistas de risco, incubadoras, universidades e institutos de pesquisa.

Cabe ressaltar que muitas transformações ainda são necessárias, para que, desde o início da vida acadêmica, os alunos vislumbrem a possibilidade de aproveitar as muitas tecnologias que estão disponíveis nas universidades.

Uma destas transformações é o ensino e a preparação dos discentes e dos docentes para que sejam capazes de identificar oportunidades de mercado e para que estejam capacitados a gerir uma empresa.

Outra mudança deve ocorrer na cultura e nas normas institucionalizadas dentro do ambiente acadêmico, pois muitos professores ainda consideram que a atividades das universidades devem estar desligadas das empresariais.

É possível observar que a formação de spin-offs acadêmicos constitui uma forma eficiente de transferir para a sociedade o conhecimento gerado nas universidades; por isso este mecanismo precisa ser debatido e algumas de suas pendências, como a faltas de patentes, devem ser resolvidas, para que mais benefícios possam ser gerados por ele.

Por fim, acredita-se que com o passar do tempo e com maior discussão sobre as potencialidades dos spin-offs acadêmicos, mais empresas surgirão e maior será o impacto que elas trarão à sociedade, visto que, com o esclarecimento dos atores envolvidos, muitas das barreiras, que hoje impedem seu crescimento, deixarão de existir.

\section{Artigo recebido em 17.02.2006. Aprovado em 30.10.2006.}

\section{ReferênCIAS BibliográficAs}

Azevedo, G. C. I. (2005).

Transferência de tecnologia através de spin-offs: os desafios enfrentados pela UFSCar. Dissertação de mestrado. Universidade Federal de São Carlos, São Carlos, SP, Brasil.
Bank Boston Economics Department. (1997, March)

MIT the impact of innovation. Bank Boston Economics Department. Recuperado em 24 maio, 2005, de http:web.mit.edu/news office/ founders/founders2.pdf 
Bray, M. J., \&

Lee, J. N. (2000).

University revenues from technology transfer: licensing fees vs. equity positions. Journal of Business Venturing, 15(5-6), 385-392.

Brisolla, S. N. (1998).

Relação universidade-empresa: como seria se fosse. In J. R. Ferreira (Org.). Interação universidade empresa. Brasília: Instituto Brasileiro de Informação em Ciências e Tecnologia.

Campomar, M. C. (1983).

As atividades de marketing no processo de transferência de tecnologia oriunda de institutos de pesquisa governamentais. In J. Marcovitch (Coord.). Administração em Ciência e Tecnologia. São Paulo: Edgard Blücher.

Carayannis, E. G.,

Rogers, E. M.,

Kurihara, K., \&

Albritton, M. M. (1998).

High-technology spin-offs from de government R\&D laboratories and research universities. Technovation, 18(1), 1-11.

Chiesa, V., \&

Piccaluga, A. (2000).

Exploitation and diffusion of public research the case of academic spinoff companies in Italy. $R \& D$ Management, 30(4), 329-340.

Duff, E. J., \&

Hilton, J. (1999).

Evolution of a sucessfull western european technology transfer organisation. In A. Inzelt \& J. Hilton (Orgs.). Technology Transfer: from invention to Innovation.
Netherlands: Kluwer Academic Publisers.

Etzkowitz, H. (1998).

The norms of entrepreneurial science: cognitive effects of new university-industry linkages. Research Policy, 27(8), 823-833.

Goldfarb, B., \&

Henrekson, M. (2003).

Bottom-up versus top-down policies towards the commercialization of university intellectual property. Research Policy, 32(4), 639-658.

Grandi, A., \&

Grimaldi, R. (2005).

Academics' organizational characteristics and the generation of successful business ideas. Journal of Business Venturing, 20(6), 821-845.

Grynszpan, F. (1999).

A visão empresarial da cooperação com a universidade. Revista de Administração, 34(4), 23-31.

Harmon, B.,

Ardishvili, A.,

Cardozo, R.,

Elder, T.,

Leuthold, J.,

Parshall, J.,

Raghian, M., \&

Smith, D. (1997).

Mapping the university technology transfer process. Journal of Business Venturing, 12(6), 423-434.

Huylebroeck, G. G. (1999).

Technology transfer from RTOs: definition/setting the scene. In A. Inzelt \& J. Hilton (Orgs.). Technology transfer: from invention to Innovation. Netherlands: Kluwer Academic Publisers. 
Pérez, M. P., \&

Sánchez, A. M. (2003).

The development of university spinoffs: early dynamics of technology transfer and networking. Technovation, 23(10), 823-831.

Prysthon, C., \&

Schmidt, S. (2002).

A experiência do Leaal/UFPE na produção e transferência de tecnologia. Ciência da Informação, 31(1), 84-90.

Rappert, B.,

Webster, A., \&

Charles, D. (1999).

Making sense of diversity and reluctance: academic-industrial relations and intellectual property. Research Policy, 28(8), 873-890.

Rogers, E. M., \&

Steffensen, M. (1999).

Spin-offs. In D. C. Dorf (Ed.). Handbook of technology management. Boca Raton, FL: CRC Press and IEEE Press.

Rogers, E. M.,

Takegami, S., \&

Yin, J. (2001).

Lessons learned about technology transfer. Technovation, 21(4), 253-261.

Sánchez, A. M., \&

Pérez, M. P. (2002, novembro).

Centros de innovácion y spin-offs académicos: el caso de Aragón. Anais do Simpósio de Gestão da Inovação Tecnológica, São Paulo, SP, Brasil, 21.

Sant'Anna, S. R. (1994, outubro).

Spin-offs universitários: um estudo exploratório. Anais do Simpósio de Gestão de Inovação Tecnológica, São Paulo, SP, Brasil, 18.
Sbragia, R. (2003).

Os determinantes de êxito de empresas de base universitária: a necessidade de um modelo de avaliação. Boletim do Núcleo de Política e Gestão Tecnológica da Universidade de São Paulo, (35), Ano 10, 1-3.

Souza, J. A., Neto (1983).

Dinamização da transferência vertical de tecnologia: diagnóstico e proposição de uma alternativa. In J. Marcovitch (Coord.). Administração em ciência e tecnologia. São Paulo: Edgard Blücher.

Steffensen, M.,

Rogers, E. M., \&

Speakman, K. (2000).

Spin-offs from research centers at a research university. Journal of Business Venturing, 15(1-2), 93-111.

Torkomian, A. L. V. (1997).

Gestão de tecnologia na pesquisa acadêmica: o caso de São Carlos. Tese de doutorado. Universidade de São Paulo, São Paulo, SP, Brasil.

Upstill, G., \&

Symington, D. (2002).

Technology transfer and the creation of companies: the CSIRO experience. $R \& D$ Management, 32(3), 233-239.

Webster, A., \&

Etzkowitz, H. (1998).

Toward a theoretical analysis of academic-industry collaboration. In $\mathrm{H}$. Etzkowitz, A. Webster, \& P. Healey (Orgs.). Capitalizing knowledge: new intersections of industry and academia. Albany: State University of New York. 